\title{
OTIMIZAÇÃO DA PRODUÇÃO DE SALGADOS EM UMA EMPRESA DE BUFFET: UMA APLICAÇÃO DE PROGRAMAÇÃO LINEAR
}

\author{
Ernesto Rademaker Martins \\ Centro Universitário Augusto Motta - UNISUAM \\ (radmart@gmail.com) \\ Bruno Da Cunha Germano \\ Centro Universitário Augusto Motta - UNISUAM \\ (brunocgermano@hotmail.com) \\ Rodilei Jose Pinheiro Da Silva \\ Centro Universitário Augusto Motta - UNISUAM \\ (rodilei.11@gmail.com)
}

\begin{abstract}
RESUMO
O mercado consumidor vem levando as empresas a oferecerem cada vez mais produtos de qualidade e com o menor custo. Para se ter vantagem competitiva, as empresas precisam obter um eficiente plano de produção, otimizando seus recursos e aprimorando seus processos. O objetivo deste trabalho é minimizar o custo de produção em uma empresa de buffet localizada na cidade do Rio de Janeiro, com o auxílio da programação linear. Foi utilizado o método simplex na otimização do problema, com o auxílio de software LINDO (Linear Interactive and Discrete Optimizer). Assim se pode analisar a quantidade ideal para se atender um evento realizado por essas empresas, resultando em uma economia anual de aproximadamente $\mathrm{R} \$ 4.405,44$.
\end{abstract}

Palavra-chave: Custo, Minimizar, Programação Linear, LINDO.

\begin{abstract}
The consumer market has led companies to offer them more and more quality products at the lowest cost. To have a competitive advantage, companies need to get an efficient production plan, optimizing their resources and improving their processes. The objective of this work is to minimize the cost of production in a buffer company located in the city of Rio de Janeiro, with the aid of linear programming. The simplex method was used to optimize the problem, with the help of LINDO (Linear Interactive and Discrete Optimizer) software. This way, one can analyze the ideal quantity to attend an event held by these companies, resulting in an annual savings of approximately \$4,405.44.
\end{abstract}

Keyword: Cost, Minimize, Linear Programming, LINDO.

\section{Como Citar:}

MARTINS, Ernesto Rademaker; GERMANO, Bruno Da Cunha; SILVA, Rodilei Jose Pinheiro Da. OTIMIZAÇÃO DA PRODUÇÃO DE SALGADOS EM UMA EMPRESA DE BUFFET: UMA APLICAÇÃO DE PROGRAMAÇÃO LINEAR. In: SIMPÓSIO DE PESQUISA OPERACIONAL E LOGÍSTICA DA MARINHA, 19., 2019, Rio de Janeiro, RJ. Anais [...]. Rio de Janeiro: Centro de Análises de Sistemas Navais, 2019. 


\section{INTRODUÇÃO}

A competição entre as empresas está cada vez mais acirrada, levando as organizações a buscarem melhores desempenhos organizacionais, utilizando estratégias que possibilitem o crescimento no mercado. Isso exige das empresas produtos de qualidade com o menor custo. A gestão da produção foca sempre em melhores métodos para aprimorar seu processo, seja em serviço ou produtos, tendo como meta principal alcançar maior lucro.

Para ser competitivo precisa-se ter controle sobre os custos dos processos, buscando a melhoria na atividade produtiva e determinando a melhor utilização de seus recursos para encontrar a solução ótima no plano de produção. Uma das metodologias disponível é a Programação Linear que é considerada uma eficiente ferramenta para programação de produção (Lachtermacher, 2004)

Andrade (2015) afirma que atualmente um dos maiores desafios que as empresas enfrentam é o de se manter competitivas no mercado e no ambiente de negócios, onde este se encontra em constante mudança. As ações estratégicas da empresa devem ocorrer de acordo com as complexidades exigidas por esse ambiente.

De acordo Hillier e Lieberman (2010) a PO é aplicada a problemas reais da sociedade, envolvendo a condução e coordenação das operações (atividades) de uma organização.

A organização em estudo é uma empresa que presta serviços em buffet de pequeno porte situada na zona oeste do Rio de Janeiro, produzindo diversos tipos e volumes de salgados, entre outros, para realizações de festas no Estado do Rio de Janeiro, e não há nenhum planejamento da produção e nenhuma metodologia que possa ser controlado e planejado sua produção a fim de obter maior lucro.

Atualmente a empresa não utiliza nenhuma ferramenta para auxiliar no planejamento e controle para cada demanda de seus produtos, sendo as informações de cada matériasprimas parte da experiencias dos colaboradores envolvidos no processo, não havendo um parâmetro para que seja definido seu planejamento produtivo e com isso a impossibilidade de saber se pode gerar ganhos maiores ou menores se comparado com planejamento da produção utilizando uma ferramenta para auxiliar na tomada de decisão.

Esse trabalho tem por finalidade apresentar métodos matemáticos, através da utilização da Pesquisa Operacional para minimizar os custos no plano de produção de salgados em uma empresa de Buffet. Para resolução do problema foi utilizado o Software Linear Interactive and Discrete Optimizer (LINDO).

\section{FUNDAMENTAÇÃO TEÓRICA}

A ciência que objetiva fornecer ferramentas quantitativas ao processo de tomada de decisão, trata-se da Pesquisa Operacional, que é constituída por um conjunto de disciplinas isoladas tais, como Programação Linear, Teoria das filas, Simulações, Programação Dinâmica, etc.

Santos (2013) afirma que a PO lança mão de modelos matemáticos e/ou lógicos, a fim de resolver problemas reais, apresentando um caráter eminentemente multidisciplinar. Assim sendo, de acordo com o tipo e com a complexidade do problema a ser estudado, serão 
escolhidos os melhores modelos que aderem àquela realidade.

O termo PO aparece pela primeira vez em 1939, porém apenas após a Segunda Guerra Mundial essa área foi se expandindo. Terminada a guerra, os ingleses reduziram os gastos destinados à pesquisa no campo da defesa do território nacional, gerando a liberação de muitos especialistas em PO das organizações militares no mesmo momento em que as empresas destruídas pelas bombas tentavam se reerguer (ACKOFF; SASIENI, 1977).

Para as metodologia de PO de todo o problema que é proposto a ser resolvido são geralmente metodologias relativamente lógica e simples de forma encadeada, tendo início com uma situação problemática, ou seja, com um descompasso entre o que se pretende com o que se há, seja para uma pessoa, um grupo de pessoas ou uma organização. Sendo assim, a primeira etapa na solução de um problema é elucidar o mesmo de sua condição.

Para uma melhor gestão do seu planejamento e controle da produção é necessário definir o melhor processo para que possa alcançar os objetivos definidos pelo nível estratégico de sua empresa.

Russomano (2000, p.5), define sistema de produção como um [...]” processo organizado, que utiliza insumos e os transforma em bens ou executa serviços, ambos devem se apresentar dentro dos padrões de qualidade e preço e ter procura efetiva”. O sistema de produção de uma empresa industrial pode ser representado conforme mostra a figura 1.

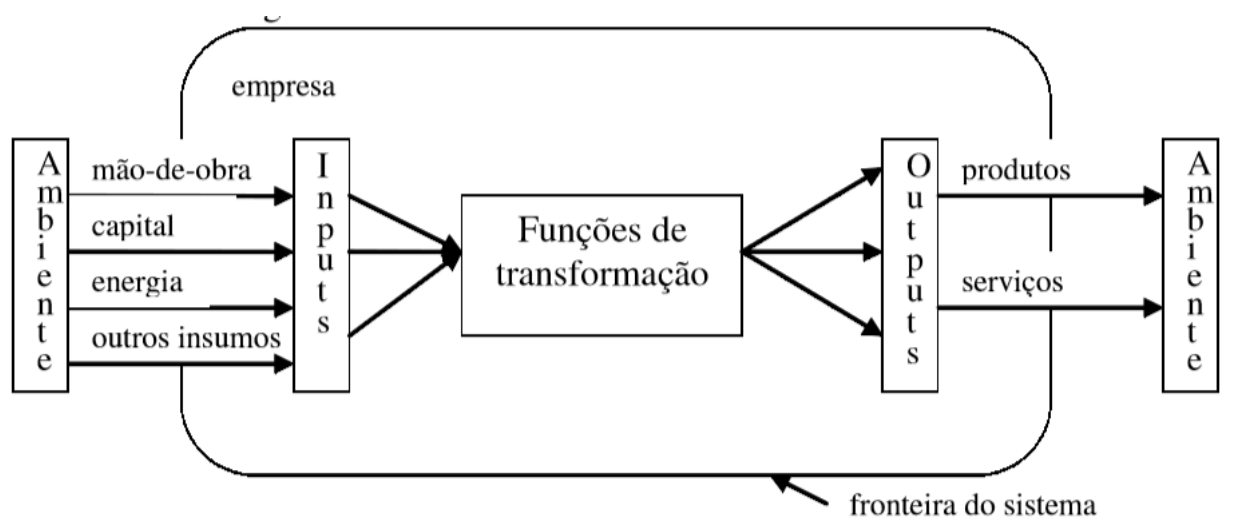

Figura 1 - sistema de produção

Fonte: Martins e Laugeni, 2005, p.11

A programação linear é umas das metodologias mais eficiente dentro da PO, pois busca de forma quantitativa a solução ótima, por meio de vendas da melhor combinação dos produtos disponíveis, obter maior lucratividade otimizando recursos.

A Programação Linear, geralmente utilizada por software, dentre os existentes tem-se LINDO, desenvolvido pelo Lindo Systems Inc., de Chicago, EUA. Segundo Oliveira et al (2015), o LINDO é considerado uma das melhores ferramentas de resolução de modelos de otimização, ele maximiza os lucros e minimiza os custos nos problemas constantes de uma empresa, tais como, transportes, planejamento da produção, entre outros. Seu resultado é confiável e aceitável em situações simples e complexas.

\section{METODOLOGIA}

A metodologia constitui em apresentar uma pesquisa bibliográfica que fundamentasse teoricamente este trabalho, e assim ter entendimento do problema encontrado e determinar a sua solução através de coletas de dados necessários referente a sua produção.

O local onde ocorreu a levantamento de dados foi na área de produção de salgados, e 
após entrevista com o gerente e o funcionário responsável pela fabricação dos salgados pode-se verificar o processo de produção, a quantidade disponibilizada nos eventos, preços de compra de insumos e receitas dos salgados.

Os dados levantados foram organizados em uma planilha do software Excel, onde foram feitos os devidos cálculos para se encontrar os dados específicos do modelo. Logo depois foi montado o modelo do problema para se chegar a uma solução ótima através do software LINDO.

\section{ESTUDO DE CASO}

\subsection{A EMPRESA}

O estudo de caso foi realizado em uma empresa especializada em serviço de buffet para casamento, aniversários, festas infantis, bodas e eventos empresariais. Atuando no mercado há 8 anos, a Buffet Paraíso Real está situada na Zona Oeste do Rio de Janeiro, onde além de realizar as festas no salão de festa próprio, oferece serviços de buffet domiciliar ou em empresas, realizando em média 20 eventos por mês. Embora a empresa ofereça um cardápio completo nas festas, o estudo de caso está relacionado apenas a produção de salgados fritos que serão servidos no evento

\subsection{PRODUÇÃO DE SALGADO}

A empresa possui uma máquina de fazer salgado da marca Gastromixx duplo recheio com contador digital (Figura 2), ela faz diversos tipos de formatos de salgados de $8 \mathrm{~g}$ a $230 \mathrm{~g}$,

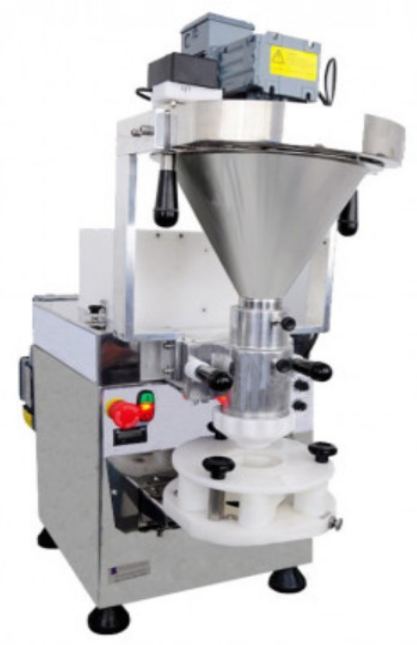

segundo suas especificações e em média, $75 \%$ do salgado é composto de massa e $25 \%$ de recheio. Para escolher a quantidade de cada sabor, o gerente usa de sua experiência e intuição, dividindo em números iguais. 
Para efeito de estudo, será usado como exemplo uma festa de casamento para 200 convidados, onde são servidos 3.000 salgados fritos divididos entre 12 sabores, sendo 250 de cada.

\subsection{MODELAGEM DO PROBLEMA}

O objetivo do modelo é minimizar o custo de produção, achando a quantidade ótima de quantos salgados de cada sabores devem ser servidos no evento. Foram coletadas as receitas dos elementos que serão utilizados na produção realizada pela empresa, observando a quantidade necessárias e o custos de cada ingrediente, como mostra a Tabela 1.

\begin{tabular}{|c|c|c|}
\hline \multicolumn{2}{|c|}{ Valor dos ingredientes } & \\
\hline Ingrediente & Quant. (Kg) & Valor \\
\hline Massa Salgada & 35,000 & 108,32 \\
\hline Frango & 4,125 & 37,50 \\
\hline Queijo & 2,500 & 49,50 \\
\hline Presunto & 0,625 & 10,62 \\
\hline Camarão & 1,875 & 25,99 \\
\hline Catupiry & 1,000 & 18,18 \\
\hline Azeitona & 0,625 & 14,03 \\
\hline Calabresa & 3,500 & 38,46 \\
\hline Massa de Kibe & 13,250 & 85,99 \\
\hline
\end{tabular}

Tabela 1: Ingredientes para a produção de 3.000 salgados Fonte: Autores (2019)

Em seguida, foram definidas as variáveis de decisão do problema, cada sabor de salgado está relacionado a uma variável e foi calculado seu preço unitário através de sua receita e o valor total de produção, descritos na Tabela 2 . 


\begin{tabular}{|c|c|r|r|r|}
\hline Variável & Salgado & $\begin{array}{c}\text { Valor } \\
\text { Unitário }\end{array}$ & $\begin{array}{c}\text { Quant. } \\
\text { Produzida }\end{array}$ & $\begin{array}{c}\text { Valor de } \\
\text { Produção }\end{array}$ \\
\hline $\mathrm{x} 1$ & Coxinha & $\mathrm{R} \$ 0,0919$ & 250 & $\mathrm{R} \$ 22,97$ \\
\hline $\mathrm{x} 2$ & Bolinha de queijo & $\mathrm{R} \$ 0,1454$ & 250 & $\mathrm{R} \$ 36,36$ \\
\hline $\mathrm{x} 3$ & Bolinha de queijo com presunto & $\mathrm{R} \$ 0,1384$ & 250 & $\mathrm{R} \$ 34,60$ \\
\hline $\mathrm{x} 4$ & Bolinha de queijo com azeitona & $\mathrm{R} \$ 0,1520$ & 250 & $\mathrm{R} \$ 38,01$ \\
\hline $\mathrm{x} 5$ & Bolinha de calabresa & $\mathrm{R} \$ 0,1014$ & 250 & $\mathrm{R} \$ 25,34$ \\
\hline $\mathrm{x} 6$ & Risole de frango & $\mathrm{R} \$ 0,1223$ & 250 & $\mathrm{R} \$ 30,59$ \\
\hline $\mathrm{x} 7$ & Risole de camarão & $\mathrm{R} \$ 0,1581$ & 250 & $\mathrm{R} \$ 39,53$ \\
\hline $\mathrm{x} 8$ & Almofada de calabresa com catupiry & $\mathrm{R} \$ 0,1086$ & 250 & $\mathrm{R} \$ 27,14$ \\
\hline $\mathrm{x} 9$ & Almofada de frango com catupiry & $\mathrm{R} \$ 0,1010$ & 250 & $\mathrm{R} \$ 25,24$ \\
\hline $\mathrm{x} 10$ & Kibe & $\mathrm{R} \$ 0,1298$ & 250 & $\mathrm{R} \$ 32,45$ \\
\hline $\mathrm{x} 11$ & Kibe com catupiry & $\mathrm{R} \$ 0,1532$ & 250 & $\mathrm{R} \$ 38,29$ \\
\hline $\mathrm{x} 12$ & Kibe com calabresa & $\mathrm{R} \$ 0,1523$ & 250 & $\mathrm{R} \$ 38,07$ \\
\hline & & $\mathrm{T}$ Total & 3000 & $\mathbf{3 8 8 , 5 9}$ \\
\cline { 2 - 5 } & & & &
\end{tabular}

Tabela 2: Custos de produção Fonte: Autores (2019)

\subsubsection{Função Objetiva}

Após a identificação das variáveis de decisão e seus custos, pode-se definir a função objetiva do problema, descrita abaixo:

F.O. $=\min \{0,0919 \mathrm{X} 1+0,1454 \mathrm{X} 2+0,1384 \mathrm{X} 3+0,1520 \mathrm{X} 4+0,1014 \mathrm{X} 5+0,1223 \mathrm{X} 6+$ 0,1581 X7 + 0,1008 X8 + 0,0932 X9 + 0,1376 X10 + 0,1446 X11 + 0,1581 X12

\subsubsection{Restrições}

Para realizar a formulação das restrições observou-se os seguintes casos:

$1^{\circ}$ Caso: Quantidades total de salgados.

Quantidade: X1 + X2 + X3 + X4 + X5 + X6 + X7 + X8 + X9+X10 + X11 + X12 >=3000

$2^{\circ}$ Caso: Somatório de cada ingrediente contido em cada salgado multiplicado pela sua variável de decisão, sendo menor ou igual a quantidades usada na produção atual.

Massa: 0,015 X1 + 0,015 X2 + 0,015 X3 + 0,015 X4 + 0,015 X5 + 0,0175 X6 + 0,0175 X7 $+0,015 \times 8+0,015 \times 9<=35$

Frango: $0,005 \mathrm{X} 1+0,0075 \mathrm{X} 6+0,004 \mathrm{X} 9<=4,125$

Queijo: 0,005 X2 + 0,0025 X3 + 0,0025 X4 <= 2,5

Presunto: $0,0025 \mathrm{X} 3<=0,625$

Camarão: 0,0075 X7 <= 1,875

Catupiry: $0,001 \mathrm{X} 8+0,001 \mathrm{X} 9+0,002 \mathrm{X} 11<=1,75$

Azeitona: $0,0025 \times 4<=0,625$

Calabresa: 0,005 X5 + 0,004 X8 + 0,005 X12 <=3,5

Massa de Kibe: 0,02 X10 + 0,018 X11 + 0,015 X12<=13,25

$3^{\circ}$ Caso: Por determinação do gerente, para se ter todas as opções de sabores, delimitou uma quantidade mínima de 100 salgados de cada tipo. 
$\mathrm{X} 1>=100$

$\mathrm{X} 2>=100$

X3 $>=100$

$X 4>=100$

$\mathrm{X} 5>=100$

$X 6>=100$

$X 7>=100$

$\mathrm{X} 8>=100$

$\mathrm{X} 9>=100$

$\mathrm{X} 10>=100$

$\mathrm{X} 11>=100$

$\mathrm{X} 12>=100$

$4^{\circ}$ Caso: Também se delimitou que a quantidade dos salgados do tipo "bolinha" fosse maior ou igual a 600, os "risoles" maior ou igual a 300, os do tipo "almofada" igual ou superior a 300 e também os do tipo "Kibe" igual ou superior a 600.

$\mathrm{X} 2+\mathrm{X} 3+\mathrm{X} 4+\mathrm{X} 5>=600$

$\mathrm{X} 6+\mathrm{X} 7>=300$

$\mathrm{X} 8+\mathrm{X} 9>=300$

$\mathrm{X} 10+\mathrm{X} 11+\mathrm{X} 12>=600$

\subsubsection{Software LINDO}

Foi utilizado o software LINDO (Linear Interactive and Discrete Optimizer) para minimizar os custos de produção achando a quantidade ótima de cada sabor de salgado.

\subsubsection{Solução do modelo}

Para se achar a solução ótima, o software realizou 26 interações chegando a um custo mínimo conforme mostra a Figura 2.

\begin{tabular}{|c|c|c|}
\hline \multicolumn{3}{|c|}{ OBJECTIVE FUNCTION VALUE } \\
\hline 1) & 367.4125 & \\
\hline $\begin{array}{r}\text { VARIABLE } \\
\text { X1 } \\
\text { X2 } \\
\text { X3 } \\
\text { X4 } \\
\text { X5 } \\
\text { X6 } \\
\text { X7 } \\
\text { X8 } \\
\text { X9 } \\
\text { X10 } \\
\text { X11 } \\
\text { X12 }\end{array}$ & $\begin{array}{c}\text { VALUE } \\
421.665802 \\
274.999817 \\
250.000000 \\
100.000000 \\
520.000000 \\
100.000000 \\
200.000000 \\
100.000000 \\
316.667725 \\
325.000519 \\
291.666107 \\
100.000000\end{array}$ & $\begin{array}{r}\text { REDUCED COST } \\
0.000000 \\
0.000000 \\
0.000000 \\
0.000000 \\
0.000000 \\
0.000000 \\
0.000000 \\
0.000000 \\
0.000000 \\
0.000000 \\
0.000000 \\
0.000000\end{array}$ \\
\hline
\end{tabular}

Figura 2: Resultado obtido pelo software LINDO

Fonte: Autores (2019)

Sendo assim, a Tabela 3 lista a quantidade ótima encontrada para cada salgado. Como o software não conseguiu achar uma solução ótima com números inteiros, optou-se 
por arredondar os valores.

\begin{tabular}{|c|c|}
\hline Salgado & $\begin{array}{c}\text { Quant. } \\
\text { Sugerida }\end{array}$ \\
\hline Coxinha & 462 \\
\hline Bolinha de queijo & 275 \\
\hline Bolinha de queijo com presunto & 250 \\
\hline Bolinha de queijo com azeitona & 100 \\
\hline Bolinha de calabresa & 480 \\
\hline Risole de frango & 100 \\
\hline Risole de camarão & 200 \\
\hline Almofada de calabresa com catupiry & 150 \\
\hline Almofada de frango com catupiry & 267 \\
\hline Kibe & 325 \\
\hline Kibe com catupiry & 292 \\
\hline Kibe com calabresa & 100 \\
\hline Tabela 3: Solução Ótima \\
Fonte: Autores (2019)
\end{tabular}

\section{ANÁLISES E DISCURSÕES}

Através das quantidades sugeridas pelo software LINDO chegou-se a um custo de produção de $\mathrm{R}$ \$ 367,41, uma redução de $\mathrm{R}$ \$ 21,18. Embora pareça um valor pequeno, devese lembrar que se trata apenas de um dos itens servidos nas festas, esse exemplo pode ser repetido para os salgados de forno, os refrigerantes, os petiscos entre outros, diminuindo ainda mais os custos. Como a empresa realiza grande volume de eventos, em média 5 por semana, pode-se chegar a uma economia anual de $\mathrm{R} \$ 4.405,44$.

\section{CONCLUSÃO}

Por meio da Pesquisa operacional a empresa ganhou vantagem competitiva em relação aos seus concorrentes, conseguindo fornecer seus serviços com um custo menor. A programação da produção e a otimização de seus recursos tornaram-se fatores estratégicos para o aumento da produtividade.

Através da programação linear, utilizando o software LINDO chegou-se a uma redução de R $\$ 4.405,44$ por ano, podendo ser ainda maior se for utilizada em outros itens, somete com otimização de recursos da empresa. Portanto, o estudo de caso, alcançou seu objetivo de produzir os salgados necessários, com os recursos disponível, com o menor custo possível.

\section{REFERÊNCIAS}


LACHTERMACHER, Gerson. Pesquisa Operacional na Tomada de Decisões. 2. ed. Rio de Janeiro: Campus, 2004. 384 p.

GOLDBARG, Marco Cesar e LUNA, Henrique Paccal. Otimização combinatória e programação linear: modelos e algoritmos. 2.ed. Rio de Janeiro: Elsevier, 2005. 649 p.

CAIXETA-FILHO, José Vicente. Pesquisa Operacional: técnicas de otimização aplicadas a sistemas agroindustriais. São Paulo: Atlas, 2001. 171 p.

MOREIRA, Daniel Augusto. Administração da Produção e Operações. São Paulo: Pioneira Thomson Learning, 2004. 619 p.

ACKOFF, Russell L.; SASIENI, Maurice W. Pesquisa Operacional. 3.ed. Rio de Janeiro: Livros Técnicos e Científicos Editora S.A., 1977

ANDRADE, Eduardo Leopoldino de. Introdução à Pesquisa Operacional: métodos e modelos para análise de decisões. 5ª ed. Rio de Janeiro: LTC, 2015.

HILLIER, F. S.; LIEBERMAN, G. J. Introduçao à Pequisa Operacional. Porto Alegre: Bookmann, 2010.

SANTOS, Marcos. Simulação da Operação de um Sistema Integrado de Informações para o atendimento préhospitalar de emergência no município do Rio de Janeiro. Dissertação de M.Sc., COPPE/UFRJ, Rio de Janeiro, Brasil, 2013.

RUSSOMANO, Victor Henrique. Planejamento \& Controle da Produção. 6. ed. São Paulo: Pioneira, 2000. 320 p.

DODGE, Mark e STINSON, Craig. Microsoft Excel 2000 - Guia Autorizado. São Paulo: Makron Books, 2001. 1016 p.

CENTERMAQ, 2019

Disponível em <https://www.centermaqequipa.com.br/maquina-de-fazer-salgados-4000-h-8g-a230g-duplo-recheio-com-contador-digital.html>. Acesso em 28 de Mai. De 2019.

OLIVEIRA, I. H. I de. et al. Utilização da pesquisa operacional para otimização de rotas de um motorista autônomo na região de São Paulo. In: SIMPÓSIO DE EXCELÊNCIA EM GESTÃO E TECNOLOGIA, 12., Resende - RJ, 2015. 